Please do not remove this page

RMIT

UNIVERSITY

\title{
A new approach to professional learning for academics teaching in next generation learning spaces
}

De La Harpe, Barbara; Mason, Thembi

https://researchrepository.rmit.edu.au/esploro/outputs/9921862231801341/filesAndLinks?institution=61RMIT_INST\&index=null

De La Harpe, B., \& Mason, T. (2014). A new approach to professional learning for academics teaching in next generation learning spaces. International Perspectives on Higher Education Research, 12, 219-239. https://doi.org/10.1108/S1479-362820140000012015

Document Version: Accepted Manuscript

Published Version: https://doi.org/10.1108/S1479-362820140000012015

Repository homepage: https://researchrepository.rmit.edu.au

Copyright (c) 2014 by Emerald Group Publishing Limited

Downloaded On 2023/04/26 13:25:38 +1000 
Thank you for downloading this document from the RMIT Research Repository.

The RMIT Research Repository is an open access database showcasing the research outputs of RMIT University researchers.

RMIT Research Repository: http://researchbank.rmit.edu.au/

\section{Citation:}

De La Harpe, B and Mason, T 2014, 'A new approach to professional learning for academics teaching in next generation learning spaces', International Perspectives on Higher Education Research, vol. 12, pp. 219-239.

See this record in the RMIT Research Repository at:

https://researchbank.rmit.edu.au/view/rmit:31430

Version: Accepted Manuscript

Copyright Statement: (c) 2014 by Emerald Group Publishing Limited

Link to Published Version:

http://dx.doi.org/10.1108/S1479-362820140000012015 


\title{
A new approach to professional learning for academics teaching in Next Generation Learning Spaces
}

\begin{abstract}
The promise of Next Generation Learning Spaces appears to remain unfulfilled. This chapter explores why and how the design of professional learning for academics teaching in such spaces can and should be transformed. It takes a fresh look at why old professional development is failing and proposes a new way to engage academics in their own professional learning. Rather than continuing with traditional professional development that is most often, ad hoc, formal, and centrally driven, comprising mandated professional development workshops and a website that may only be visited once, the chapter explores the move from 'old' professional development to 'new' professional learning. It draws on the fields of organisational theory, cognitive theory and behavioural economics.

New professional learning is characterised by a 'pull' rather than a 'push' philosophy. Academic staff themselves drive their own learning, choosing what, when and how they want to learn to become better teachers. Multiple and various learning opportunities embedded in day to day work are just-in-time, self-directed, performance-driven and evaluated within an organisational system. In this way the institutional setting influences behaviour by 'nudging' habits and setting defaults resulting in academics making the "right" decisions and doing the "right" thing. By addressing the compelling issue of how to enhance academic staff teaching capability, this chapter can help university leaders to think beyond the professional development approaches of yesterday. Aligning with this new direction will result in enhanced learning and teaching in the future.
\end{abstract}

Keywords: Professional learning, professional development, staff capability, learning and teaching, change management, transformative learning

Acknowledgements: We would like to acknowledge the Australian Government Office for Learning and Teaching who provided the support for the project: Not a Waste of Space: professional development for staff teaching in Next Generation Learning Spaces, although the views expressed in this publication do not necessarily reflect the views of the Australian Government Office for Learning and Teaching. We would also like to thank all those involved in the Not a Waste of Space project: Megan McPherson (Project Manager, RMIT University), Sheona Thomson (Queensland University of Technology), A/Professor Kenn Fisher (University of Melbourne), Dr Wesley Imms (University of Melbourne), A/Professor Kym Fraser (Victoria University) and Diana Taylor (Curtin University). In addition, the project team would especially like to thank Dr Emily Koethe, Lauren Ferro and Nick Faulkner for their contribution.

\section{Current context}

The university landscape is shifting (Barber, Donnelly \& Rizvi, 2013; Bokor, 2012; Bok, 2013). The role of the university in society as creators and guardians of knowledge is being challenged. The value add of universities is also coming under question as knowledge becomes more and more ubiquitous and available online. Competition from private providers and global tertiary players is putting pressure on universities in attracting and retaining students. Student expectations are also changing. Digital technologies are transforming the way students engage in their learning and the student learning experience.

Additionally, lectures are slowly disappearing from universities. Teaching spaces are being turned into Next Generation Learning Spaces to encourage a different type of learning and 
teaching. Spaces are being built or retrofitted to increase active learning and a more studentcentred approach to teaching. While Next Generation Learning Spaces vary in their exact characteristics, they typically are:

- carefully planned to facilitate interactions between groups of students;

- designed for large numbers of students and allow for flexible use and arrangement of furniture;

- constructed to enable the academic to both teach and facilitate the class from anywhere in the room; and

- technology-enabled to encourage active learning.

Next Generation Learning Spaces are claimed to be 'disruptive', pressing academics to rethink their teaching approach. According to Oblinger (2005, p.14), "[a]n active, collaborative teaching and learning philosophy is often manifested in a different design. Space can either enable - or inhibit - different styles of teaching as well as learning". The new design of Next Generation Learning Spaces requires a re-conceptualization of pedagogy to maximise their effectiveness (Oblinger, 2005). There is no 'front' in a Next Generation Learning Space, with tables arranged so that large numbers of students working in groups can share work using technology. It is more difficult to lecture with students sitting in small groups, with half the class with their backs to the front.

To date, universities around the world have spent millions of dollars transforming teaching spaces into next generation learning spaces. For example, the US spent around US\$50 billion between 2004 and 2007 on university physical facilities (Oblinger, 2005). In the UK, $£ 902$ million went towards university capital grants in 2008 (HEFCE, 2008) and £562 million was set aside for 2010-2011 initiatives (HEFCE, 2010). In Australia, the Government injection of "...more than $\$ 5$ billion is transforming Australia's tertiary landscape - with universities, TAFEs and training centres as well as science and research facilities getting a much needed makeover... This investment was long overdue, serving to address decades of neglect and bring campuses across the country into the 21st century"(DIISRT, 2012, p.3-4).

Despite this considerable investment in Next Generation Learning Spaces there is evidence that the full potential of these spaces is not yet being fully realised. For some academics, this kind of teaching environment encourages them to (re)think their pedagogy and practice to one that is active, student-centred, technology-rich and authentic. For others, support is needed to help them do so. Next Generation Learning Spaces require universities to rethink how to support staff to make the much needed shift in teaching for enhanced learning. As the Educause Learning Initiative Advisory Board (2009, p. 63) point out, "[w]ith all the tools now available to us, a failure to create expansive, inclusive, and active learning environments would dishonor the mission of higher education...".

\section{Professional development now}

Traditionally, universities have supported academic staff to enhance their teaching practice, including for teaching in Next Generation Learning Spaces in a number of ways. Typically these include short, intensive in-house training/induction activities; a series of centrally run workshops that are often ad hoc and disjointed; a certified tertiary teaching and learning program; or by supporting attendance at disciplinary-based conferences. In addition, most universities would have a generic website dedicated to teaching and learning. Where online 
modules are available they are often a component of induction focussing on compliance education, including topics such as, ethics, equity, copyright and occupational health and safety, rather than learning and teaching.

Hart (2011, p.1), points out that for many organisations "...the current state of workplace learning is one where there is a heavy focus on formal, content-rich courses...". Such "just-incase' professional development may or may not directly deal with academic staff current needs. In addition, traditional professional development approaches often lead to a superficial accumulation of knowledge, layer upon layer, rather than an ongoing reconceptualisation of educational practice (Boud \& Hager, 2012; Cross, 2010; Feixas \& Zellweger, 2010; Hart, 2011; Webster-Wright, 2009). Levine (2006, p.109) likens many contemporary professional development programs for enhancing teaching to"...the fabled Wild West town...unruly and disordered".

Moreover, professional development that comprises workshops as the main strategy for academics to attend at set times, or 'just-in-case', have been found to be insufficient in developing the professional teaching expertise of academics that, in turn, impact on student outcomes (Hattie, 2009; Parsons, Hill, Holland \& Willis, 2012).

As far back as the mid-80s, questions have been raised around the impact of such traditional professional development approaches. A meta-analysis of 91 studies that explored the effectiveness (or not) of professional development concluded that "...of all the different types of training structures, independent study is the most effective" (Wade, 1985, p. 54). Similarly, the study by Birman, Desimone, Porter and Garet (2000) found that "[a]n activity is more likely to be effective in improving teachers' knowledge and skills if it forms a coherent part of a wider set of opportunities for teacher learning and development". Additionally, Timperley, Wilson, Barrar and Fung (2007) found that professional learning is most effective if it uses active learning strategies and is offered over time.

Academics are often resistant to engaging in professional development activities, citing lack of time or lack of relevance of program to their context. Low attendance is not uncommon. A significant lack of attendance is often reported by those running professional development activities (workshops/conferences), despite academic staff registering. This rings true for all professional development. A study of continuous professional development (CPD) for dentists (Barnes, Bullock, Bailey, Cowpe \& Karaharju-Suvanto, 2013, p.5) found that the factors preventing engagement in CPD "... included time since graduation, costs, work and home commitments...interest and convenience" and barriers to implementing changes to workplace practices were around "...availability of materials, resources and support from colleagues".

Additionally, the culture of academia is not encouraging of professional development. Most academics are employed by universities based on their expertise in a research field. As Bok (2013, p. 2-3) points out of universities in America “... high regard in...[global rankings]...is largely due to the excellence of their research rather than the quality of education they provide". Academics are not required to have a teaching qualification despite teaching being a significant part of their role. It is assumed that academics keep up with their teaching knowledge through their research, including through reading, collaboration with colleagues, publishing and attendance at discipline focused conferences. Thus, the teaching aspect of their role is often taken for granted. For many academics, "[s]pending time on training 
courses is time spent avoiding the main purpose of a lecturer's raison d'etre at a university research" (Quinn, 2012, p.73).

Lastly, the beliefs academics hold about teaching also influences whether they will engage with professional development or not (Quinn, 2012). Quinn identified four beliefs that impacted on academic staff engagement with professional development, as follows:

- a belief that the main purpose of their role is to research and that universities reward researching (engaging in professional development for teaching is not important)

- a belief that students are the problem since they are underprepared and not at the standard required (engaging in professional development not required rather students need development)

- a belief that teaching is simple, intuitive focused on skill development and there is nothing to learn about it (engaging in professional development is not needed since teaching is easy)

- a belief that engaging in professional development is to fulfil a policy, or meet a personal strategic intent, such as gaining promotion (engaging in professional development would only be to satisfy an institutional requirement or a compliance need, or for personal gain)

In a university world where there is casualisation of staff, massification of student numbers, globalisation of the student body, growth in the use of technology, a focus on developing learner capabilities and 'agency', and a need to connect what is learned to industry, the simple truism of the intuitive 'academic' teacher is obsolete. No longer can academics ignore engaging in professional development that enhances knowledge of educational theory and contemporary practice.

There is a growing body of literature that professional development needs to become more sophisticated in order to support academics develop the capabilities that teaching of the future requires (Boud \& Hager, 2012; Cross, 2010; Hart, 2011, Hattie, 2009; Hunzicker, 2011). Finding new ways for academics to develop the capacity required of a $21^{\text {st }}$ century practitioner and to continually develop their teaching practice is needed as a matter of urgency. New ways must be found, since as reported above, the traditional, 'just-in-case' model is proving to be insufficient and not fit for purpose.

Next we describe a professional learning approach for academics that can be sustainably applied to the whole of a university rather than being simply left up to individual academics. The approach responds to the need for academics to enhance their teaching in Next Generation Learning Spaces. It was developed as part of an Australian Government Office for Learning and Teaching funded project - Not of a Waste of Space: professional development for staff teaching in Next Generation Learning Spaces. The professional learning approach allows for individualised and flexible professional learning that works for both the novice and the more experienced academic (de la Harpe \& Mason, with Koethe, Faulkner \& McPherson, 2013).

\section{New approach to professional learning}

Contemporary literature and theory reveals a number of characteristics of professional learning of the future. Professional learning is more effective if it is continuous and situated 
in work; embedded in a holistic system that is performance-driven and (self)-evaluated (Organisational theory); learner-centred, self-organised and self-managed; and if it provides opportunities to learn from others (Cognitive theory); "nudges" intentions to engage in professional learning and to make good choices; and includes an element of fun (Behavioural Economic Theory) (Adam \& de Savigny, 2012; Angner \& Loewenstein, 2010; Avineri, 2012; Ajzen, 1985; 1991; Cross, 2010; Dawnay \& Shah, 2005; Gee, 2003; 2004; 2005; 2012; Hart, 2011, Hattie, 2009; Senge, 1990; Thaler \& Sunstein, 2009; Werbach, 2012).

Based on these characteristics, a new approach to professional learning for teaching in Next Generation Learning Spaces is presented in the sections that follow. The new approach is designed to be holistic, interactive and adaptable, supporting universities in the challenge of maintaining best practice or bringing about a paradigm shift in the way academics teach in Next Generation Learning Spaces. The new approach (see Figure 1) is

- continuous and situated in work, and comprises
o a work plan strategy
o an email strategy
o online resources
o local network meetings
o posters, tear-off guides and bookmarks

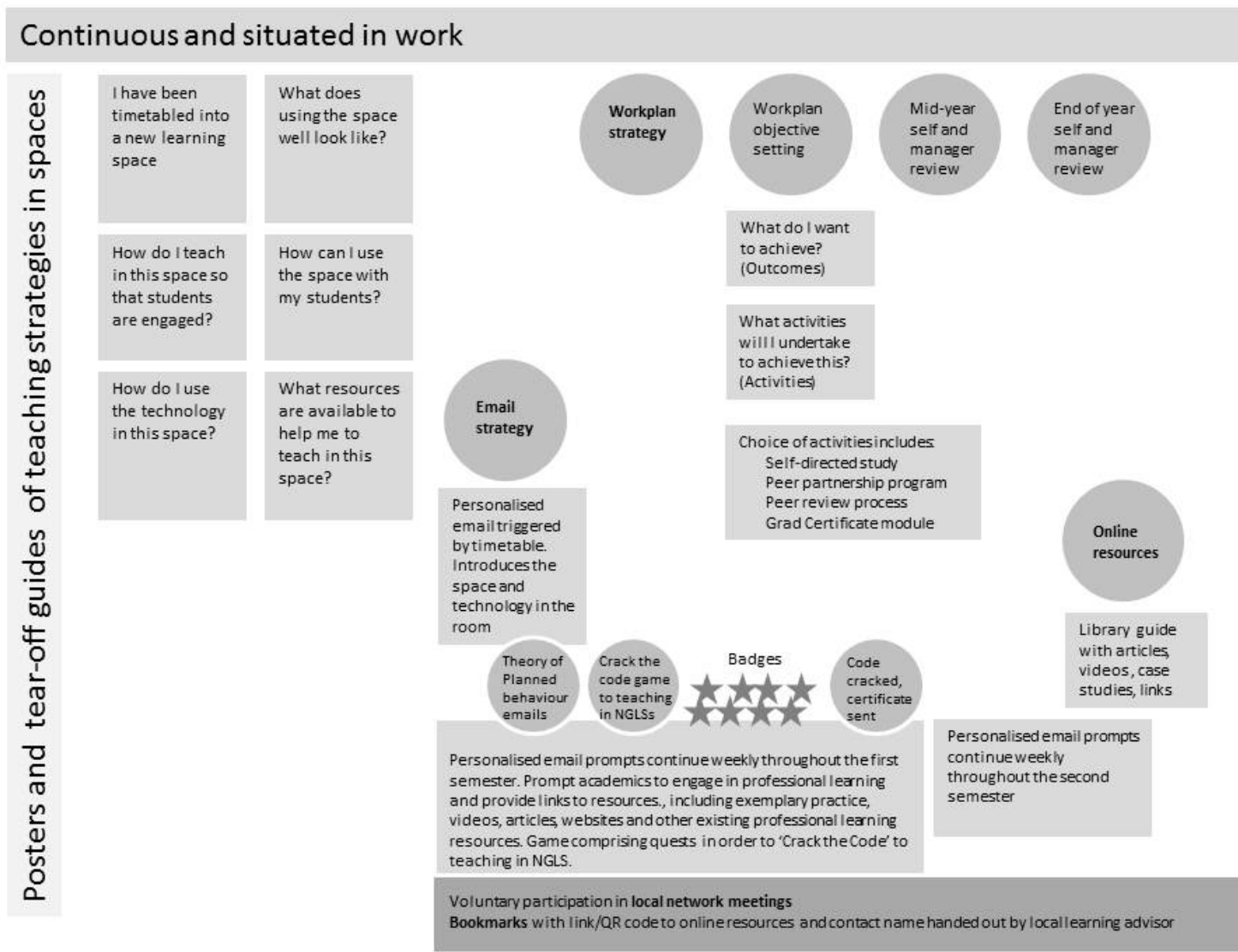

Figure 1. New professional learning approach for teaching in Next Generation Learning Spaces and elements 
In the sections below, each of the aspects and the literature that underpins them is discussed.

\section{Situated in work}

The institutional timetabling system is used to identify academic staff who are timetabled to teach in a Next Generation Learning Space. These staff are then automatically included in the professional learning approach.

Boud and Hager (2012, p.18) argue that professional learning “...must be located in what professionals do and how they do it". In their view, academic learning should be seen as,

...a normal part of working and indeed most other social activities. It occurs through practice, in work settings from addressing the work challenges and problems that arrives. Most learning takes place not through formalised activities, but through the exigencies of practice with peers and others, drawing on expertise that is accessed in response to need. Problem-solving in which participants tackle challenges which progressively extend their existing capabilities and learn with and from each other appears to be a common and frequent form of naturalist development.

(Boud \& Hager, 2012, p.22)

Recent literature suggests that locating professional learning in the practice of work, and focusing on enhancing learning rather than knowledge acquisition is most successful. Learning that is continuous and happens in the work setting has been found to be essential for workers to remain up to date. Many studies have found that this is a powerful way to learn, with "[s]tudy after study finding that at least $80 \%$ of how workers learn to do their jobs..." this way (Cross, 2010, p.45). Cross likens formal learning to taking a bus "[e]veryone starts at the same place, goes to the same destination, and arrives at the same time..." in contrast, learning that is situated in work is more like riding a bicycle where the rider is in control and able to start when they are ready, move at their own pace and change direction as required (Cross, 2010).

\section{Work plan strategy}

In the new approach, academics are responsible for their own professional learning and are accountable for taking action. This involves them creating/agreeing learning outcomes aimed at enhancing their teaching in Next Generation Learning Spaces in their annual work plan or performance review discussion, determining activities to achieve the outcomes and setting performance indicators to measure success as part of their mid (if applicable) and end of year performance review. Institutional outcomes could be cascaded to pre-populate work plans of those staff teaching in a Next Generation Learning Space where an online system is in place.

Thus, work plans with clearly stated outcomes around professional learning for teaching in Next Generation Learning Spaces are agreed with line-managers and include mid and annual review, and self and manager feedback. They are the vehicle to agree and anchor professional learning in the university system, whilst giving academics choice over their professional learning. This approach allows academics choice in what, when and how they want to learn or engage, but within a system where outcomes are evaluated. 
A number of professional learning options can be provided. This gives academics choice and allows them to begin where they are 'at' in terms of enhancing their teaching in Next Generation Learning Spaces. Some options include engaging in a Peer Partnership program or a Peer Review process, undertaking self-directed learning (including, for example, a scholarship of learning and teaching project), or completing a module from the Graduate Certificate in Tertiary Teaching and Learning. Most of these choices already exist within universities.

The work plan strategy draws on recent literature that suggests having processes that require staff to self-manage their learning needs within a clear accountability framework is most effective (Hart, 2011; Cross, 2010). It is also underpinned by Behavioural Economic theory, involving choice architecture and "nudges". Behavioural economics has shown that people are not always rational decision makers, instead they often make irrational or unpredictable decisions that appear impulsive, habitual or emotional rather than planned and which do not follow the neo-classical economic model of decision-making behaviour (Angner \& Loewenstein, 2010).

Behavioural Economic Theory (Thaler \& Sunstein, 2009) argues that rational judgment and decision-making does not always prevail and the way choices are presented influence decision making. Choice architecture does not mandate or prevent choices but rather aims to influence good choices. By designing the environment using choice architecture, individuals are 'nudged' to make the "right" decision and are not deprived of their freedom to make decisions and choices. According to Thaler and Sunstein (2009, p.4), "[g]ood [choice] architects realize that although they can't build the perfect building [professional learning program] they can make some design choices that will have beneficial effects". In line with this theory, environments are designed or changed so that defaults make it easy for people to do the "right" or make the "right" decisions that nudge habits and indirectly influence behaviour. Universities should aim to make engaging in professional development an easy choice for staff and the path of least resistance.

\section{Email strategy}

A series of 14 emails that are personalised and specifically designed for academic staff timetabled to teach in a Next Generation Learning Space are sent over the course of a teaching semester/period (see figure 2). Emails either encourage academics to undertake professional development activities and provide resources (Theory of planned behaviour emails in weeks 1, 3, 6, 9 and 11,) or invite them to participate in a professional learning game (Quest emails in weeks 2, 4, 5, 7, 8, 10, 12, 13 and 14). Academics can 'opt-out' if they do not want to continue receiving the emails.

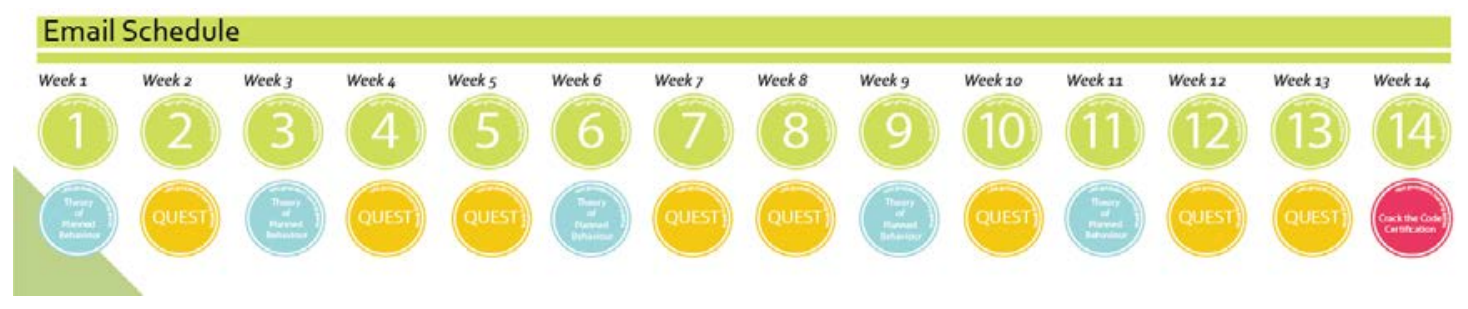

Figure 2: Email schedule showing Theory of Planned Behaviour and Quest emails 
The emails (five) that encourage academics to engage in professional learning and provide resources are underpinned by the Theory of Planned Behaviour (Ajzen, 1985). According to the theory, a person is most likely to intend to engage in a behaviour if they evaluate that behaviour positively (attitude towards the behaviour), perceive social pressure to engage in the behaviour (subjective norm) and believe that the behaviour will be easy to perform (perceived behavioural control). Emails are, therefore, designed and presented to influence attitudes, subjective norms and perceived behavioural control, since all three influence intentions to increase engagement with professional learning (see Figure 3).

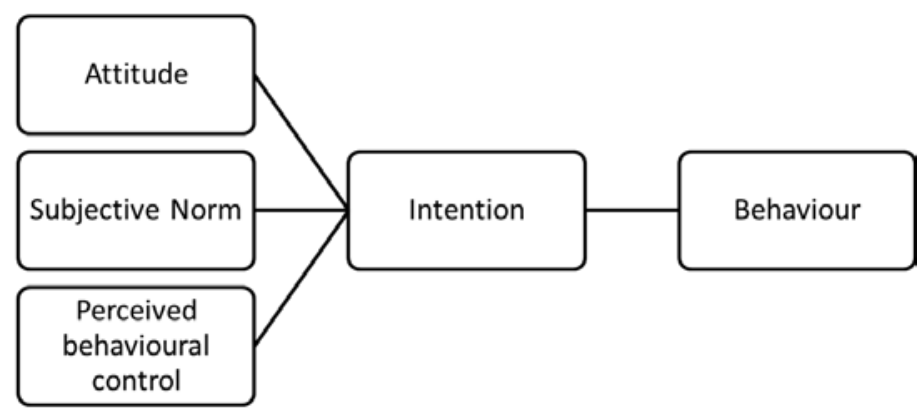

Figure 3. Elements of the Theory of Planned Behaviour

The emails (nine) that invite academics to participate in a game exploring the opportunities that Next Generation Learning Spaces offer, comprise completing 8 quests in order to "Crack the code" to teaching in Next Generation Learning Spaces (see Figure 4). At the completion of each Quest the academic receives a redeem code or passcode. They are then asked to submit this code to a website whereupon they receive a badge with a letter - one of the letters towards "cracking the 8 letter code" to teaching in a Next Generation Learning Space. Once all the letters are received and the "code is cracked" a certificate of completion from a senior university learning and teaching leader, for example, Pro-Vice Chancellor (Learning and Teaching), Deputy Vice-Chancellor (Learning and Teaching) is automatically generated.
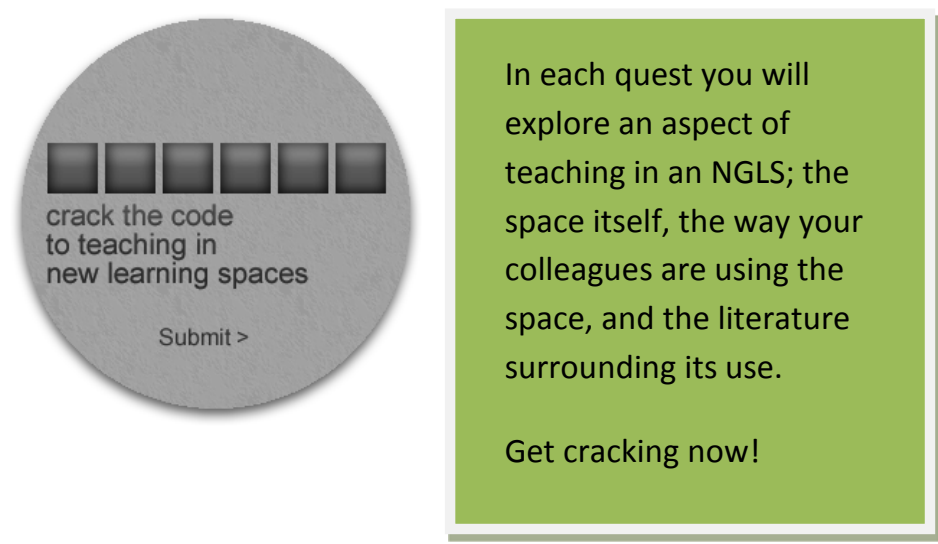

Figure 4. Introduction to "Crack the Code" to teaching in next generation learning spaces game

On the way to "cracking the code" extrinsic and intrinsic elements are included. Extrinsic elements involve for example coffee vouchers and a certificate of completion that can be used for promotion or teaching award applications. Intrinsic elements focus on providing activities that result in feelings of being supported to teach better, being helped to stay up to 
date, being on the cutting edge and being able to maintain currency. They also provide a sense of personal satisfaction from completing the quests and cracking the code.

The interactive "Crack the Code" game is underpinned by gamification theory (Werbach, 2012). Gamification is the application of game elements and techniques to activities in nongame settings, incorporating elements of social learning, competition, cooperation, exploration and storytelling. According to Gee (2012, p.xviii), people can choose to learn things from books, movies and television, but in games learning is core and unavoidable, since it is built into their design.

Those who engage in playing games do not just do things and make decisions, they learn things and master them. If they do not, they do not leave the first level of a game. Imagine a book that constantly had quizzes and tests at the end of each section (oops, that's a textbook). Few people would consider it fun (few people consider textbooks fun). But games constantly assess players. Every action is a test with feedback, and the boss at the end of a level is a "final exam" for that level. Games have found that both learning and constant assessments of that learning are a "turn-on" for people. And players pay lots of money for this turn-on. The textbook makers can only marvel in envy.

Good games work because they know that learning is a deep drive for humans, a drive that school has managed to kill for many. Games are simply spaces for learning and problem-solving with a "win" condition (beating each level and the game as a whole). But to sell, they have to organise learning in engaging and motivating ways. They have to tap into the innate drive for learning and mastery that is inside all human beings.

A continuous and targeted email strategy keeps staff engaged and provides an element of fun, 'nudging' them to do the 'right' thing.

\section{Online resources}

The very best of the numerous resources already available online are contextualised and (re)packaged in a Library Guide for academic staff teaching in Next Generation Learning Spaces. Creating a library guide about teaching in Next Generation Learning Spaces in collaboration with University Librarians is easy to do and is a sustainable approach (see http://rmit.libguides.com/newlearningspaces). Resources can include articles, videos, case studies, links to other university sites. Useful topics to include: Make the space work; Make teaching more effective, Make technology work, Manage learners well and Get ideas from colleagues. Since SpringShare software has been adopted by most universities for the creation of library guides in Australia, creating a library guide allows universities across the sector to share resources by easily adopting and adapting each other's guides.

Access to online resources which are relevant, varied, up-to-date and immediately applicable is underpinned by constructivist learning theory (Jonassen, 1994) and allows staff to build their capabilities, 'just-in-time' and 'just-for-me', supporting learner-centred and self-directed learning (Zimmerman, 1989).

\section{Network meetings}

Academics timetabled to teach in Next Generation Learning Spaces are personally invited to form a local school network. Network meetings allow academic staff teaching in Next 
Generation Learning Spaces to get together regularly during the teaching period. Ideally meetings are formed and facilitated in-context, by a person responsible for learning and teaching leadership and/or support in the school. A moderate budget for catering and for guest speakers should be provided.

It is important that meetings are contextualised depending on the needs of the academic staff and, thus, can be organised in different ways. For example, external guest speakers can be invited to prompt discussion about teaching in Next Generation Learning Spaces; academics in the school can be invited staff to speak about how they teach in a Next Generation Learning Space; facilitated sessions for staff to bring along their 'problems of practice' in teaching in these spaces for peer feedback and discussion can also be arranged.

Local network meetings are underpinned by social constructivist learning theory. They provide face-to-face, peer supported and social networking opportunities for academic staff to discuss and share their approaches to teaching in Next Generation Learning Spaces for those who want to learn in this way.

Posters, tear-off guides and bookmarks

Posters that focus on the negative impact of a didactic approach to teaching, for example student dis-

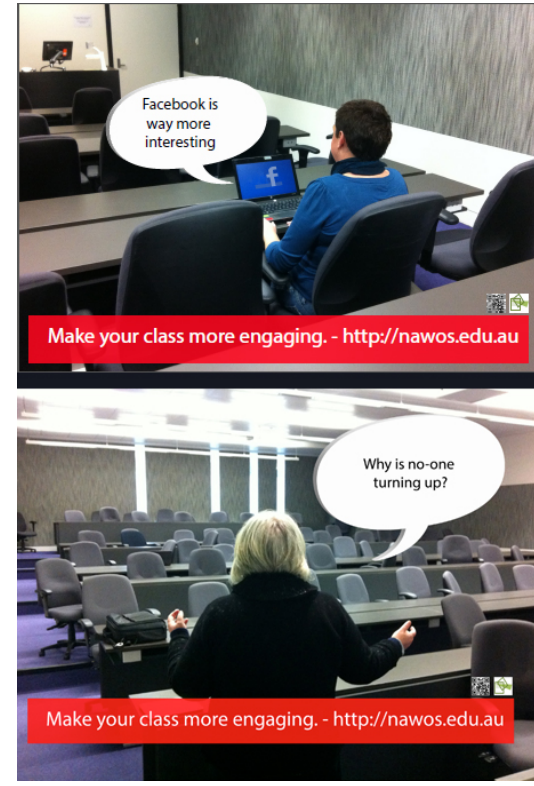

Figure 5. Posters using loss aversion theory engagement and non-attendance are designed for display in Next Generation Learning Spaces (see Figure 5). These posters prompt academic staff to reflect on their teaching approach and their student responses to their teaching in Next Generation Learning Spaces.

Posters draw on the theory of loss aversion research (a component of behavioural economic theory) which suggests that negative messages about what might be lost are more effective in changing behaviour than positive messages about what can be gained (Kahneman \& Tversky, 2000; Fuller, 2009). Loss aversion theory has been successfully employed by the Transport Accident Commission and stop drinking and smoking campaigns.

Tear-off guides placed in Next Generation Learning Spaces describe teaching strategies that encourage more interactive use of the space, and provide step by step instructions on how to implement them. Examples of strategies include "Think-Pair-Share", "Plus-MinusInteresting" or "Role playing" (see Figure 6). Academics teaching in the spaces can 'tear off' these guides to adapt their teaching.

Bookmarks refer staff to online resources and provide the name of the local learning and teaching leader/support in the school. QR codes are provided so that academic staff can simply go straight to the online resources using a QR reader on their phone or tablet making it easy for them to access information. 


\section{Plus/Minus/Interesting or PMI}

\begin{abstract}
What is it?
Plus/Minus/interesting is an Edward de Bono strategy that requires students to direct their thinking from different angles and consider multiple ideas.

\section{How does it work?}

Ask students to write down all the pluses, then minuses and finally, the interesting points on a particular topic or experience. Students should spend time thinking about each point or question and can do this either individually or in groups.

\section{Why use it?}

The PMI strategy encourages exploration of new ideas and can help students be more open-minded. In a group situation the activity allows students to share and build upon ideas.
\end{abstract}

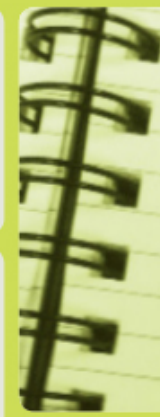

How can it be used?

- To encourage students to think open-mindedly before studying a controversial issue

- To help students evaluate a text, issue, debate etc

- To encourage students to evaluate their own work and to provide a framework for peer feedback or assessment

\section{Resources}

- Paper, pens

- Whiteboard, whiteboard markers

Online: Open up Google docs or a wiki page and add three columns.

Other:

Tricider (https://tricider.com/) is a online collaboration tool for brainstorming and debate.

Training video: http://www.teachertrainingvideos.com/tricider/index.html

Figure 6. Tear-off guide

The tear-off guide and bookmark strategies are underpinned by behavioural economic theory, specifically choice architecture and "nudge" theory, since they are designed to provide easy access to information and effective teaching strategies and to "nudge" academics to try them. They also act as prompts to remind and encourage i.e. "nudge" staff to engage in professional learning.

\section{Professional learning of the future}

In this chapter a new approach was presented for transforming the professional learning of academics teaching in Next Generation Learning Spaces which can be sustainably applied across a university and not simply left up to individual academics.

The approach is set within a rigorous, organisational accountability framework, as well as being performance-driven and (self)-evaluated, making it a core part of a dynamic and 
complex whole of organisation system. The work plan strategy anchors professional learning in work ensuring that academics take responsibility for their own professional learning and are held accountable for taking action. It allows academics choice in what, when and how they want to learn or engage, but within a system where outcomes are supported and evaluated. This element signals that the organisation supports academic engagement in professional learning and as a result contributes to improving the culture of professional learning in academia. A culture that encourages professional learning has been shown to be one of the most successful ways to impact student outcomes positively (Hattie, 2009).

In the new approach behavioural economic theory, specifically choice architecture, is applied responsibly in a number of ways to "nudge" staff to make good professional learning choices. Firstly, academic staff, who are teaching in Next Generation Learning Spaces are identified through the timetabling system and are automatically included in a purposefully designed and contextualised email strategy. Secondly, individualised learning outcomes for enhancing teaching in Next Generation Learning Spaces are negotiated or automatically cascaded into academic staff work plans. Thirdly, in work plans, academic staff are given a choice of professional learning activities from which to choose. Fourthly, resources are made easily available to staff through emails that provide links to online resources and tear-off guides placed in Next Generation Learning Spaces that "nudge" academics to think about trying something new. Finally, bookmarks are distributed with a link/QR code to online resources and the name of an academic staff developer whom they could contact for support. Thus, the use of choice architecture makes it easier for people to make the "right" decisions or to do the "right" thing. This is achieved by making positive and helpful changes to the environment that "nudge" habits and set defaults.

The professional learning approach outlined above is also based around systems thinking. The use of systems thinking recognises that the professional learning of academics is complex and has many interacting components (Adam \& de Savigny, 2012; Senge, 1990). By taking into account aspects of the institutional context, lost opportunities for improving the teaching of academics when ad hoc and 'just-in-case' initiatives are offered can be mitigated (see Figure 7). 


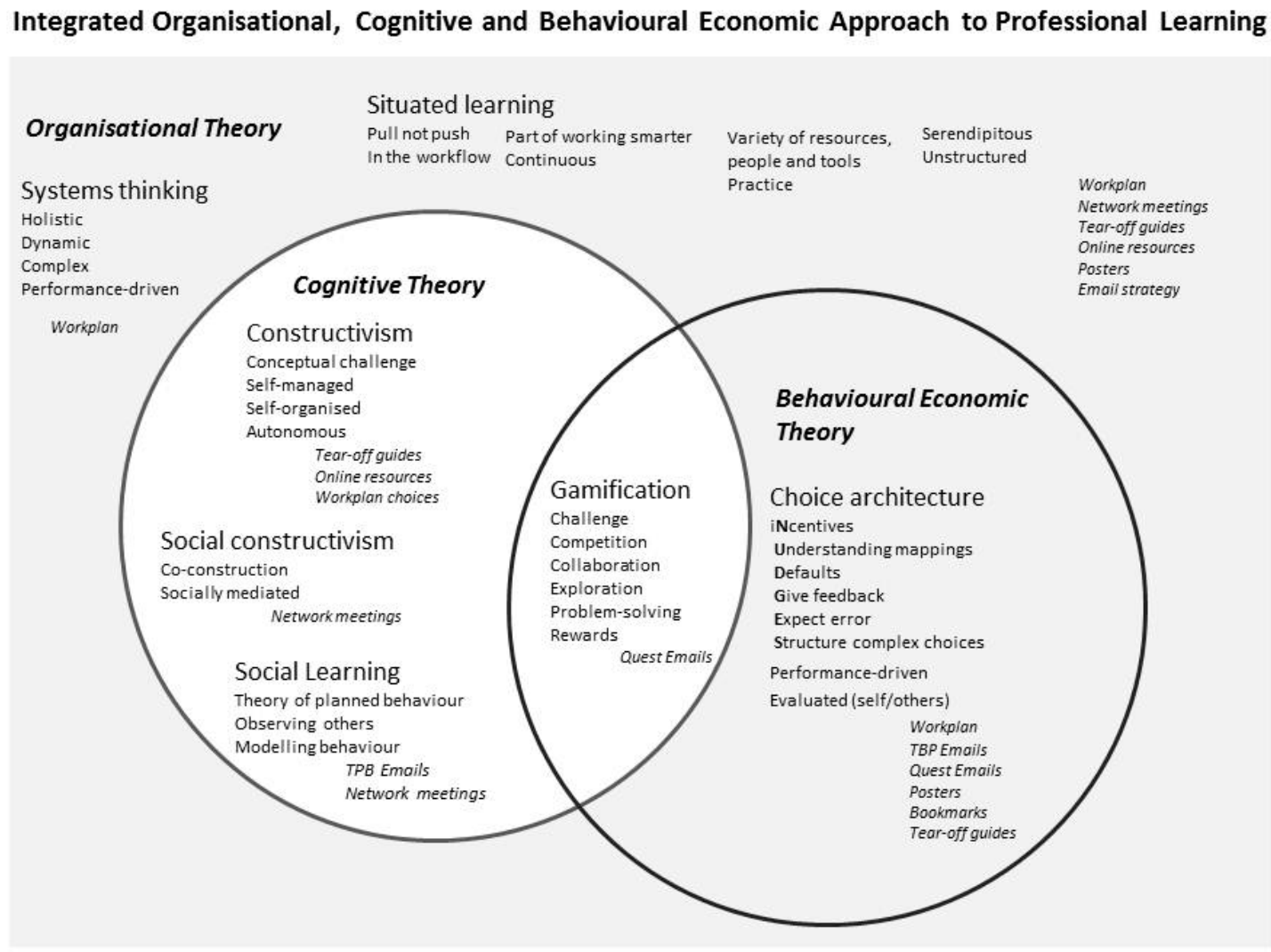

Figure 7. Professional learning approach for teaching in Next Generation Learning Spaces showing theories

A more contemporary approach to professional learning is embedded in day to day work and is performance-driven and (self)-evaluated. It is underpinned by a "pull" philosophy and driven by academic staff learning. It is set within a context that encourages self-direction and good decision making. It includes multiple opportunities that are just-in-time, just for me and are fun and engaging. Overall, professional learning of the future:

1. is continuous and situated in work

2. is embedded in a holistic system that is performance-driven and (self)-evaluated

3. is learner-centred, self-organised and self-managed

4. is enriched by learning with and from one another

5. is supportive of making good choices "nudging" intentions to engage in professional learning and

6. is fun using elements of gamification

Next Generation Learning Spaces encourage students to have much greater agency in their learning and encourage a project-based curriculum, mirroring industry practice. Students engage within a carefully scaffolded learning environment in both formal and informal ways, working with others and on their own, finding out information, following up on a question through Google, listening to other students or discussing an issue with their teacher.

If universities want students to be active, lifelong learners taking responsibility for their own learning then the system that is set up for academics to learn about good teaching should parallel this approach. In so doing, academics can be supported to understand the ways that 
teaching and learning pedagogies have changed and start to internalise a new set of pedagogical norms. Knowing "how to teach" and "how to use technology" in Next Generation Learning Spaces is essential. Professional learning of the future, like effective student learning, is active and student-centred, with online and face-to-face components as required (de la Harpe \& Mason, with contributions from Koethe, Faulkner \& McPherson, 2013).

The promise of Next Generation Learning Spaces cannot remain unfulfilled. By addressing the compelling issue of staff professional learning, this chapter can help senior university leaders to think beyond the professional development approaches of yesterday. It offers an institutional framework that enables a new professional learning approach, resulting in enhanced learning and teaching and an improved culture of teaching for the future. Whilst the design of Next Generation Learning Spaces are meant to "nudge" academics into new ways of teaching, this chapter has demonstrated that universities also need a "nudge" to find new ways of supporting the professional learning of academics teaching in these spaces.

\section{References}

Adam, T. \& de Savigny, D. (2012). Systems thinking for strengthening health systems in LMICs: need for a paradigm shift. Health Policy and Planning;27, iv1-iv3.

Ajzen, I. (1985). From intentions to actions: A theory of planned behavior. In J. Kuhl \& J. Beckman (Eds.), Action-control: From cognition to behaviour (pp. 11-39). Heidelberg: Springer.

Ajzen, I. 1991. The theory of planned behavior. Organisational Behavior and Human Decision Processes, 50, 179-211.

Angner, E. \& Loewenstein, G. (2010). Behavioral economics. In: U. Mäki (Ed.), Handbook of the Philosophy of Science. Philosophy of Economics, vol. 13. Elsevier, Amsterdam

Avineri, E. (2012). On the use and potential of behavioural economics from the perspective of transport and climate change. Journal of Transport Geography, 24, 512-521.

Barber, M., Donnelly, K. \& Rizvi, S. (2013). An avalanche is coming: higher education and the revolution ahead. London: Institute for Public Policy Research. Retrieved from: http://www.ippr.org/images/media/files/publication/2013/04/avalanche-iscoming_Mar2013_10432.pdf

Barnes, E., Bullock, A.D., Bailey, S.E.R., Cowpe, J.G., \& Karaharju-Suvanto, T. (2013). A review of continuing professional development for dentists in Europe. European Journal of Dental Education, 17(1), 23-28.

Bokor, J. (2012). University of the future: A thousand year old industry on the cusp of profound change. Ernst and Young: Australia. Retrieved from:

http://www.ey.com/Publication/vwLUAssets/University_of_the_future/\$FILE/University _of_the_future_2012.pdf

Bok, D. (2013). Higher Education in America. New Jersey: Princeton University Press.

Birman, B.F., Desimone, L., Porter, A.C., \& Garet , M.S. (2000). Designing professional development that works. Educational leadership, May, 28-33. Retrieved from: http://cemse.uchicago.edu/computerscience/OS4CS/landscapestudy/resources/Birm an-Desimone-Porter-and-Garet-2000.pdf 
Boud, D. \& Hager, P. (2012). Re-thinking continuing professional development through changing metaphors and location in professional practices. Studies in Continuing Education, 34(1), 17-30.

Cross, J. (2010). They had people called professors. . . ! Changing worlds of learning: strengthening informal learning in formal institutions? In U. Ehlers and D. Schneckenberg, (Eds.), Changing Cultures in Higher Education (pp. 43-54). Berlin Heidelberg: Springer.

Dawnay, E. \& Shah, H. (2005). Behavioural Economics: Seven Principles for Policy-makers. New Economics Foundation, London, UK. Retrieved from: http://www.neweconomics.org/publications/entry/behavioural-economics

de la Harpe, B. \& Mason, T. with Koethe, E., Faulkner, N. \& McPherson, M. (2013). Not a Waste of Space: Professional development for staff teaching in Next Generation Learning Spaces, ID11-2050. Final report to the Australian Government Office for Learning and Teaching, Melbourne.

DIISRT (2012). Building a smarter future: Australia's cutting-edge tertiary education and research facilities. Report of the Australian Government Department of Industry, Innovation, Science, Research and Tertiary Education, DIISRTE 12/217. Retrieved from http://www.innovation.gov.au/highereducation/ResourcesAnd Publications/HigherEducationPublications/Documents/BuildingASmarterFuture.pdf

EDUCAUSE Learning initiative Advisory Board (2009). Opening up learning: from spaces to environments. EDUCAUSE Review, 44(3), 62-63.

Feixas, M., \& Zellweger, F. (2010). Faculty development in context: changing learning cultures in Higher Education. In U. Ehlers and D. Schneckenberg, (Eds.), Changing Cultures in Higher Education (pp. 85-102). Berlin Heidelberg: Springer.

Fuller, J. (2009). Heads, you die: bad decisions, choice architecture, and how to mitigate predictable irrationality. Per Capita Research Paper, Melbourne. Retrieved from: http://www.percapita.org.au/01_cms/details.asp?ID=215

Gee, J. P. (2003). What video games have to teach us about learning and literacy. New York: Palgrave/Macmillan.

Gee, J. P. (2004).Situated language and learning: a critique of traditional schooling. London: Routledge.

Gee, J. P. (2005).Why video games are good for your soul: pleasure and learning. Melbourne: Common Ground.

Gee, J. P. (2012). Forward. In C. Steinkuehler, K. Squire and S. Barab (Eds.) Games, learning and society: learning and meaning in the digital age. New York: Cambridge University Press.

Hart, J. (2011). Social learning handbook synopsis. Centre for Learning \& Performance Technologies. Retrieved from: http://c4lpt.co.uk/social-learning-handbook/sociallearning-handbook-synopsis/.

Hattie, J. (2009). Visible Learning: A synthesis of over 800 meta-analyses relating to achievement. London: Routledge.

HEFCE (2008). HEFCE supports higher education in England with increased funding of $£ 7.5$ billion. Retrieved from: http://www.hefce.ac.uk/ 
HEFCE (2010). Funding for universities and colleges in 2010-11. Retrieved from: Retrieved from: http://www.hefce.ac.uk/

Hunzicker, J. (2011). Effective professional development for teachers: a checklist. Professional Development in Education, 27(2), 177-179.

Jonassen, D. H., (1994). Thinking Technology: Toward a constructivist design model. Educational Technology, 34(3), 34-37.

Technology, 34(3), 34-37. Kahneman, D. \& Tversky, A. (2000). Choices, Values, and Frames. New York: Cambridge University Press.

Levine, A. (2006). Educating school teachers. Retrieved from http://www.edschools.org/pdf/Educating_Teachers_Report.pdf

Oblinger, D. (2005). Leading the transition from classrooms to learning spaces. EDUCAUSE Quarterly, 1, 14-18.

Parsons, D., Hill, I., Holland, J., \& Willis, D. (2012). Impact of teaching development programmes in higher education. The Higher Education Academy. UK: London.

Retrieved from

http://www.heacademy.ac.uk/assets/documents/research/HEA_Impact_Teaching_de velopment_Prog.pdf

Quinn, L. (2012). Understanding resistance: an analysis of discourses in academic staff development. Studies in Higher Education, 37(1), 69-83.

Senge, (1990). The Fifth Discipline. New York: Double Day/Currency.

Thaler, R., \& Sunstein, C. (2009). Nudge: improving decisions about health, wealth, and happiness. London: Penguin Books.

Timperley, H., Wilson, A., Barrar, H., \& Fung, I. (2007). Teacher professional learning and development: Best evidence synthesis iteration [BES]. Wellington: Ministry of Education. Retrieved from:

http://www.educationcounts.govt.nz/data/assets/pdffile/0017/

16901/TPLandDBESentire.pdf

Wade, R.K. (1985). What makes a difference in inservice teacher education? A metaanalysis of research. Educational Leadership, 42(4), 48-54.

Webster-Wright, A. (2009). Reframing professional development through understanding authentic professional learning. Review of Educational Research, 79(2), 702-739.

Werbach, K. (2012). Gamification. Coursera. Retrieved from: https://www.coursera.org/course/ gamification.

Zimmerman, B. J. (1989). Models of self-regulated learning and academic achievement. In J. Zimmermm \& D. H. Schunk (Eds.), Self-regulated learning and academic achievement: Theory, research, and practice (pp. 1-25). New York: Springer-Verlag. 